\title{
Immunophilin Regulation of Neurotransmitter Release
}

\author{
Joseph P. Steiner, ${ }^{* \dagger}$ Ted M. Dawson, ${ }^{\star}$ Majid Fotuhi, $\$$ and Solomon H. Snyder*\|\# \\ Departments of *Neuroscience, ${ }^{\ddagger}$ Neurology, "Pharmacology and \\ Molecular Sciences, and "Psychiatry and Behavioral Sciences, Johns \\ Hopkins University School of Medicine, Baltimore, Maryland, U.S.A. \\ ${ }^{\dagger}$ Department of Neurobiology, Guilford Pharmaceuticals Inc., \\ Baltimore, Maryland, U.S.A. \\ \$Department of Neuroscience, Harvard University School of Medicine, \\ Boston, Massachusetts, U.S.A.
}

\begin{abstract}
Background: The immunophilins are proteins that mediate actions of immunosuppressant drugs such as FK506 and cyclosporin A by binding to calcineurin, inhibiting its phosphatase activity, and increasing the phosphorylation level of transcription factors required for interleukin 2 formation. Though concentrations in the brain greatly exceed levels in immune tissues, no function has been previously established for nervous system immunophilins. Nitric oxide (NO) has been implicated in neurotransmitter release. FK506 appears to inhibit NO production by maintaining NO synthase in a highly phosphorylated and thereby inactivated state. Accordingly, we examined effects of FK506 and cyclosporin A on neurotransmitter release in $\mathrm{PC} 12$ cells treated with nerve growth factor (NGF) and in rat brain striatal synaptosomes. Materials and Methods: We monitored effects of immunophilin ligands on $\left[{ }^{3} \mathrm{H}\right]$-neurotransmitter release from PC12 cells differentiated with NGF. Rat brain striatal synaptosomes were loaded with radiolabeled transmitters and treated with FK506 or cyclosporin A prior to initiating neurotransmitter release with $\mathrm{N}$-methyl-D-aspartate (NMDA) or potassium depolarization. Striatal synaptosomes were also loaded with ${ }^{32} \mathrm{P}$-orthophosphate and treated with FK506. ${ }^{32} \mathrm{P}$-labeled synaptic vesicle proteins were isolated from these synaptosomes in an attempt to
\end{abstract}

relate specific FK506-dependent phosphorylation of vesicle proteins with the effects of FK506 on neurotransmitter release. Identification of proteins targetted by FK506 was made by immunoblot analysis and immunoprecipitation. Results: Low nanomolar concentrations of the immunosuppressant drugs FK506 and cyclosporin A (CsA) inhibit transmitter release from PC-12 cells and from NMDA-stimulated brain synaptosomes. By contrast, the immunosuppressants augment depolarization-induced transmitter release from synaptosomes. Synapsin I, a synaptic vesicle phosphoprotein, displays enhanced phosphorylation in the presence of FK506.

Conclusions: Inhibition of transmitter release in PC-12 cells and NMDA-treated synaptosomes by immunosuppressants may reflect augmented phosphorylation of NO synthase, reducing its catalytic activity. This fits with the requirement of NO for transmitter release in PC12 cells and NMDA-treated synaptosomes. Stimulation by immunosuppressants of transmitter release in potassium depolarized synaptosomes may result from augmented phosphorylation of synapsin I, whose phosphorylation is known to facilitate transmitter release. Thus, immunophilins may modulate release of numerous neurotransmitters both by influencing NO formation and the phosphorylation state of synaptic vesicle-associated proteins.

\section{INTRODUCTION}

The immunophilins cyclophilin and FK506binding protein (FKBP) mediate the immuno-

Address correspondence and reprint requests to: Solomon H. Snyder, Departments of Neuroscience, Pharmacology, Molecular Sciences, Psychiatry, and Behavioral Sciences, 725 N. Wolfe St, Johns Hopkins University School of Medicine, Baltimore, MD 21205, U.S.A. suppressant actions of drugs such as cyclosporin A (CsA) and FK506 (1). The immunophilins occur in substantially higher concentrations in the brain than in the immune tissues and are highly localized in discrete neuronal populations together with the calcium/calmodulin-activated phosphatase, calcineurin (2). Complexes of the immunosuppressants with the immunophilins 
bind to and inhibit the catalytic activity of calcineurin, thus increasing the phosphorylation of proteins that are calcineurin substrates $(2,3)$. FK506 and CsA potently and selectively block neurotoxicity elicited by stimulation of the $\mathrm{N}$ methyl-D-aspartate (NMDA) subtype of glutamate receptors, which have been implicated in neuronal damage associated with strokes and neurodegenerative diseases (4). This neuroprotective action appears related to enhanced phosphorylation of nitric oxide synthase (NOS) which inhibits NOS catalytic activity (4), as NOS inhibitors block NMDA neurotoxicity (5).

Despite the high levels of brain immunophilins and their involvement in neurotoxicity, a physiologic role has remained elusive. The link between immunophilins and NOS suggested a possible participation in neurotransmitter release. Nitric oxide (NO) regulates neurotransmitter release, as NOS inhibitors block transmitter release in brain synaptosomes and PC12 cells $(6,7)$. Neurotransmitter release is also regulated by the phosphorylation state of synaptic vesicle proteins like synapsin I, whose enhanced phosphorylation is associated with increased transmitter release $(8-10)$. In the present study, we show that very low concentrations of FK506 and CsA regulate release of several neurotransmitters in PC12 cells and brain synaptosomes, effects which may reflect influences on phosphorylation of NOS and synaptic vesicle proteins. These actions implicate the immunophilins in transmitter release physiology.

\section{MATERIALS AND METHODS $\left.{ }^{3} \mathrm{H}\right]-$ Neurotransmitter Release Assays}

PC12 CELLS. PC12 cells were grown in the presence of $50 \mathrm{ng} / \mathrm{ml}$ nerve growth factor (NGF) for 8-10 days, as described previously (7). At 16-18 hr prior to release assay, the cells were placed in Dulbecco's Modified Eagle's Medium (DMEM) plus NGF and $20 \mu \mathrm{M}$ choline chloride at $10^{6}$ $\mathrm{cpm} / \mathrm{ml}$. The cells were then washed three times with oxygenated $37^{\circ} \mathrm{C}$ neurotransmitter release (NTR) buffer ( $124 \mathrm{mM} \mathrm{NaCl}, 5 \mathrm{mM} \mathrm{KCl}, 1.5 \mathrm{mM}$ $\mathrm{NaHPO}_{4}, 2 \mathrm{mM} \mathrm{MgCl} 2,2 \mathrm{mM} \mathrm{CaCl}, 6 \mathrm{mM}$ glucose, $25 \mathrm{mM}$ HEPES, pH 7.25) and resuspended in $1 \mathrm{ml}$ NTR buffer. Nitro-L-arginine or FK506 was added for $5 \mathrm{~min}$ at $37^{\circ} \mathrm{C}$ followed by addition of $40 \mathrm{mM} \mathrm{KCl}$ to stimulate acetylcholine (ACh) release. After 2 min the release process was stopped by removing the supernatants and cen- trifuging for $5 \mathrm{~min}$ at $12,000 \times \mathrm{g}$. The supernatants were phosphorylated with choline kinase ( 2 milliunits $/ \mathrm{ml}$ ) to facilitate the separation of $\left[{ }^{3} \mathrm{H}\right]-\mathrm{ACh}$ from $\left[{ }^{3} \mathrm{H}\right]-$ phosphocholine. As a control for nonspecific release or leakiness of the cells, supernatants from washed cells incorporated with $\left[{ }^{3} \mathrm{H}\right]$-choline were removed just prior to addition of $\mathrm{KCl}$. These samples were processed identically as the assay samples. Values obtained from these control cells were then subtracted from the assay samples to determine specific neurotransmitter release. ACh release assays were performed in triplicate or quadruplicate in three separate experiments and data presented are mean values.

$\left[{ }^{3} \mathrm{H}\right]$-dopamine release was assayed similarly to $\left[{ }^{3} \mathrm{H}\right]-\mathrm{ACh}$ release, except that 8 - to 10 -day NGF-treated PC12 cells were treated with $\left[{ }^{3} \mathrm{H}\right]-$ dopamine $60 \mathrm{~min}$ prior to assay. Release of dopamine was stimulated by addition of $40 \mathrm{mM}$ $\mathrm{KCl}$ for $2 \mathrm{~min}$ at $37^{\circ} \mathrm{C}$. Cell supernatants were then centrifuged for $5 \mathrm{~min}$ at $12,000 \times \mathrm{g}$, and radioactivity was measured in the supernatants.

RAT BRAIN STRIATAL SYNAPTOSOMES. Striatal synaptosomes were isolated in $0.32 \mathrm{M}$ sucrose after $1,000 \times g$ centrifugation of striatal homogenates prepared with a Teflon homogenizer. The supernatant was diluted 2-fold with NTR buffer and incubated at $37^{\circ} \mathrm{C}$ for $15 \mathrm{~min}$. Crude synaptosomes were then loaded with $\left[{ }^{3} \mathrm{H}\right]$-neurotransmitter at $1 \mu \mathrm{Ci} / \mathrm{ml}$ for $30 \mathrm{~min}$ at $37^{\circ} \mathrm{C}$, washed with NTR buffer and recentrifuged at $1200 \times g$ for $15 \mathrm{~min}$. Synaptosomes were preincubated with FK506 or rapamycin for $5 \mathrm{~min}$ at $37^{\circ} \mathrm{C}$. After pretreatment, $\mathrm{KCl}$ or $\mathrm{NaCl}$ was added to 40 $\mathrm{mM}$ final concentration to evoke neurotransmitter release or provide a control, respectively. After $2 \mathrm{~min}$ of release at $37^{\circ} \mathrm{C}$, synaptosomes were centrifuged at $10,000 \times g$ for $5 \mathrm{~min}$, and released $\left[{ }^{3} \mathrm{H}\right]$-neurotransmitter was recovered in the supernatant. Nonspecific release of transmitter was estimated from $\left[{ }^{3} \mathrm{H}\right]$-transmitter recovered in the supernatant of synaptosomes centrifuged before addition of $\mathrm{KCl}$ or $\mathrm{NaCl}$. Assays were performed in triplicate in three separate experiments and mean values are reported.

\section{Phosphorylation of synaptosomal proteins}

Synaptosomes isolated from $0.32 \mathrm{M}$ sucrose homogenization were incubated for 90 min with ${ }^{32} \mathrm{P}$-orthophosphate $(0.1 \mathrm{mCi} / \mathrm{ml})$ in phosphorylation buffer $\left(26 \mathrm{mM} \mathrm{NaHCO}_{3}, 124 \mathrm{mM} \mathrm{NaCl}, 5\right.$ $\mathrm{mM} \mathrm{KCl}, 2 \mathrm{mM} \mathrm{CaCl} 2,2 \mathrm{mM} \mathrm{MgCl}, 10 \mathrm{mM}$ 
glucose, $\mathrm{pH}$ 7.2). The synaptosomes were washed three times in phosphorylation buffer and recovered by centrifugation at $10,000 \times g$ for $15 \mathrm{~min}$. Synaptosomes were then preincubated with $100 \mathrm{nM}$ FK506 or buffer for $5 \mathrm{~min}$ at $37^{\circ} \mathrm{C}$. After pretreatment, $\mathrm{KCl}$ was added to $40 \mathrm{mM}$ to stimulate transmitter release and phosphorylation. After 2 min of phosphorylation, synaptosomes were recovered by centrifugation at $10,000 \times g$ for $5 \mathrm{~min}$. Pellets were resuspended in ice cold $\mathrm{H}_{2} \mathrm{O}+50 \mathrm{mM} \mathrm{NaF}$ and $10 \mu \mathrm{M}$ sodium pyrophosphate (to prevent dephosphorylation) for $30 \mathrm{~min}$ at $4^{\circ} \mathrm{C}$, followed by a $10,000 \times g$ centrifugation to remove the lysed synaptosomes. The $10,000 \times g$ supernatant was then centrifuged at $200,000 \times g$ for $2 \mathrm{hr}$ through a 150 $\mathrm{mM}$ sucrose cushion to recover ${ }^{32} \mathrm{P}$-labeled synaptic vesicles. ${ }^{32} \mathrm{P}$-labeled synaptic vesicle proteins were separated by SDS-polyacrylamide gel electrophoresis using the buffers of Laemmli (11), the gels dried down and autoradiograms were prepared.

For immunoblot analysis, proteins from replica SDS-gels were electrophoretically transferred to nitrocellulose and probed with affinity-purified anti-synapsin I Ig (graciously provided by Dr. Pietro DeCamilli, Yale University School of Medicine).

\section{Immunoprecipitation of ${ }^{32} \mathbf{P}$-synapsin I}

Phosphorylated striatal synaptosomes treated with FK506 or buffer containing $0.01 \%$ ethanol (the vehicle for FK506) were solubilized by addition of $1 \%$ SDS. Affinity-purified antibodies to synapsin I were added to the solubilized proteins for $\mathrm{l} \mathrm{hr}$ at $40^{\circ} \mathrm{C}$ to precipitate phosphorylated synapsin I. Immune complexes were recovered by incubation with Staphylococcus aureus bearing protein A for 30 min followed by centrifugation.

\section{RESULTS}

FK506 very potently inhibits both the spontaneous as well as the potassium depolarization induced release of $\left[{ }^{3} \mathrm{H}\right]$-dopamine and $\left[{ }^{3} \mathrm{H}\right]-\mathrm{ACh}$ from PC 12 cells that have been differentiated by NGF treatment (Fig. 1). Effects on depolarization-induced dopamine release are evident with as little as $0.1 \mathrm{nM}$ FK506, while $1 \mathrm{nM}$ FK506 diminishes spontaneous and potassium depolarization-induced release of both dopamine and ACh. Maximum inhibition is evident at $10 \mathrm{nM}$ FK506 with a reduction of basal release to 50-
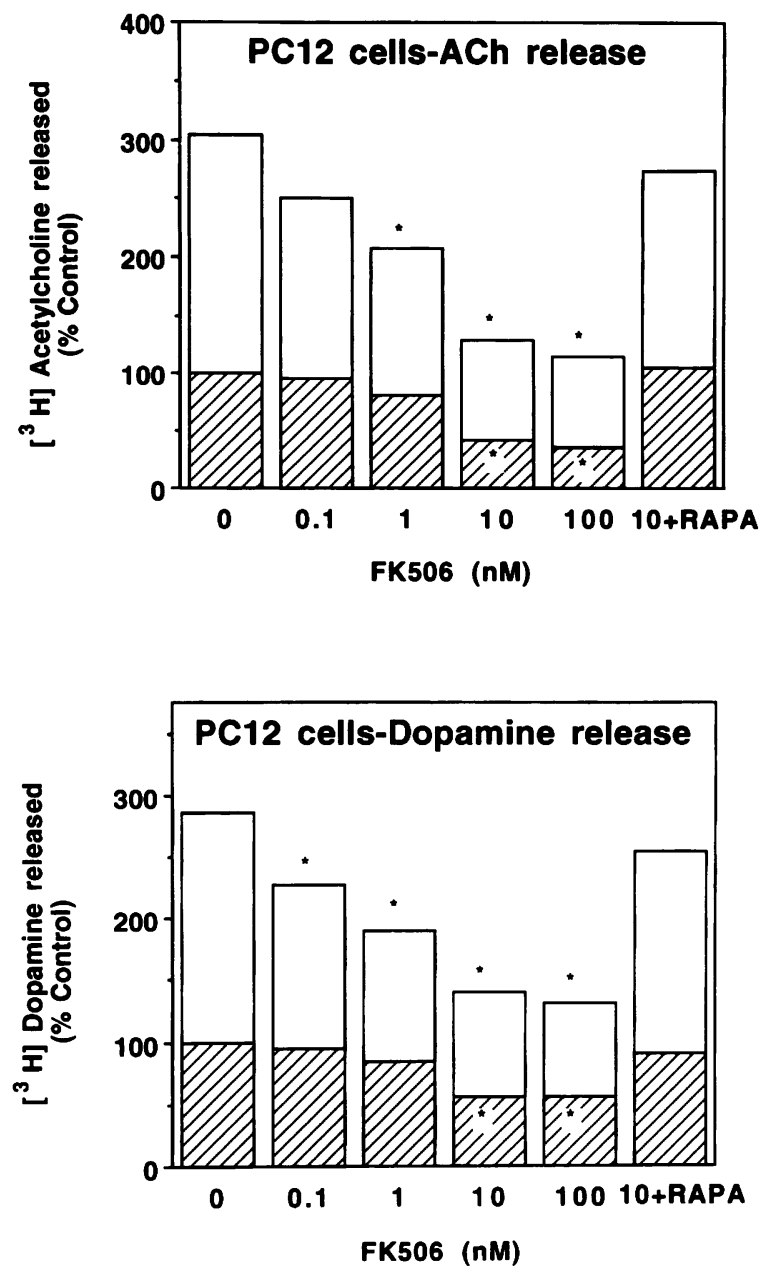

FIG. 1. FK506 inhibits release of acetylcholine (ACh) and dopamine from PCI2 cells

PC1 2 cells were cultured and $\left[{ }^{3} \mathrm{H}\right]$-neurotransmitters were released as described in Materials and Methods. Various concentrations of FK506 or FK506 + 1 $\mathrm{mM}$ rapamycin were added to the cells $5 \mathrm{~min}$ prior to addition of $\mathrm{NaCl}$ or $\mathrm{KCl}$ to initiate transmitter release. Release of $\left[{ }^{3} \mathrm{H}\right]-\mathrm{ACh}$ (upper panel) and dopamine (lower panel) was quantified as described in Materials and Methods. The amount of transmitter released by addition of $\mathrm{NaCl}$ (basal release, diagonally lined bars) in absence of drug treatment was designated $100 \%$ of control. Neurotransmitter released by addition of $\mathrm{KCl}$ is indicated by white bars. *Statistically significant differences between drug treatment and controls $(p<0.05$ using paired and unpaired Student's $t$ tests).

$60 \%$ of control levels and reduction of depolarization-induced release to $35-40 \%$ of control. Release of dopamine and ACh from NGF-treated PC1 2 cells is also inhibited by NOS inhibitors as described previously (7), confirming a role for NO in the release process. The immunosuppres- 
sant rapamycin blocks FK506 binding to its receptor protein FKBP-12 and reverses numerous effects of FK506 (12). Rapamycin (1 $\mu \mathrm{M})$ reverses influences of FK506 on both dopamine and acetylcholine release. CsA $(1 \mu \mathrm{M})$ also inhibits both spontaneous and depolarization-induced release of dopamine.

In synaptosomes prepared from the corpus striatum of rat brain, FK506 blocks NMDA-induced release of $\left[{ }^{3} \mathrm{H}\right]$-glutamate, resembling effects in PC12 cells (Fig. 2). FK506 fails to block $\left[{ }^{3} \mathrm{H}\right]$-glutamate release from synaptosomes elicited by potassium depolarization (data not shown). Nitro-L-arginine, like FK506, inhibits NMDA-induced $\left[{ }^{3} \mathrm{H}\right]$-glutamate release in synaptosomes but not depolarization elicited release. Recently, Hultsch et al. (13) noted that FK506 inhibits serotonin release from the rat basophilic leukemia cell line RBL-2H3, a mast cell model. We confirmed these findings and also noted that nitro-L-arginine inhibits this release process (data not shown).

The inhibition of neurotransmitter release by nitro-L-arginine confirmed our earlier findings indicating that NO regulates neurotransmitter release in PC12 cells and synaptosomes (7). Inhibition of neurotransmitter release is elicited in a stereospecific fashion by isomers of $\mathrm{N}$-methyl arginine and is reversed by L-arginine (7). Potassium depolarization induced release of neurotransmitters in PC1 2 cells does not appear until 8 days following NGF treatment coincident with the first appearance of NOS immunoreactivity and enzyme activity $(7,14,15)$. FK506 enhances the phosphorylation of NOS which inhibits NOS catalytic activity (16), accounting for the ability of FK506 to block NMDA-neurotoxicity in cortical cultures (4). We suggest that inhibition of neurotransmitter release in PC 12 cells by FK 506 and CsA similarly derives from enhanced phosphorylation of NOS with inhibition of NO formation.

In PC 12 cells, where the release of transmitters is due to nitric oxide production, FK506 markedly inhibits potassium-induced $\mathrm{ACh}$ and dopamine release (Fig. 1). However, in striatal synaptosomes, FK506 produces markedly different effects (Fig. 3). Both basal and potassium-induced release of $\left[{ }^{3} \mathrm{H}\right]$-dopamine, $\left[{ }^{3} \mathrm{H}\right]-\gamma$-aminobutyrate (GABA), $\left[{ }^{3} \mathrm{H}\right]$-glutamate, $\left[{ }^{3} \mathrm{H}\right]$-serotonin, and $\left[{ }^{3} \mathrm{H}\right]$-norepinephrine are enhanced by the drug, with clear-cut effects at $1 \mathrm{nM}$ concentration, some enhancement at $0.1 \mathrm{nM}$, and maximal effects at 10-100 nM. FK506 promotes the calcium-dependent release of neurotransmitters from striatal
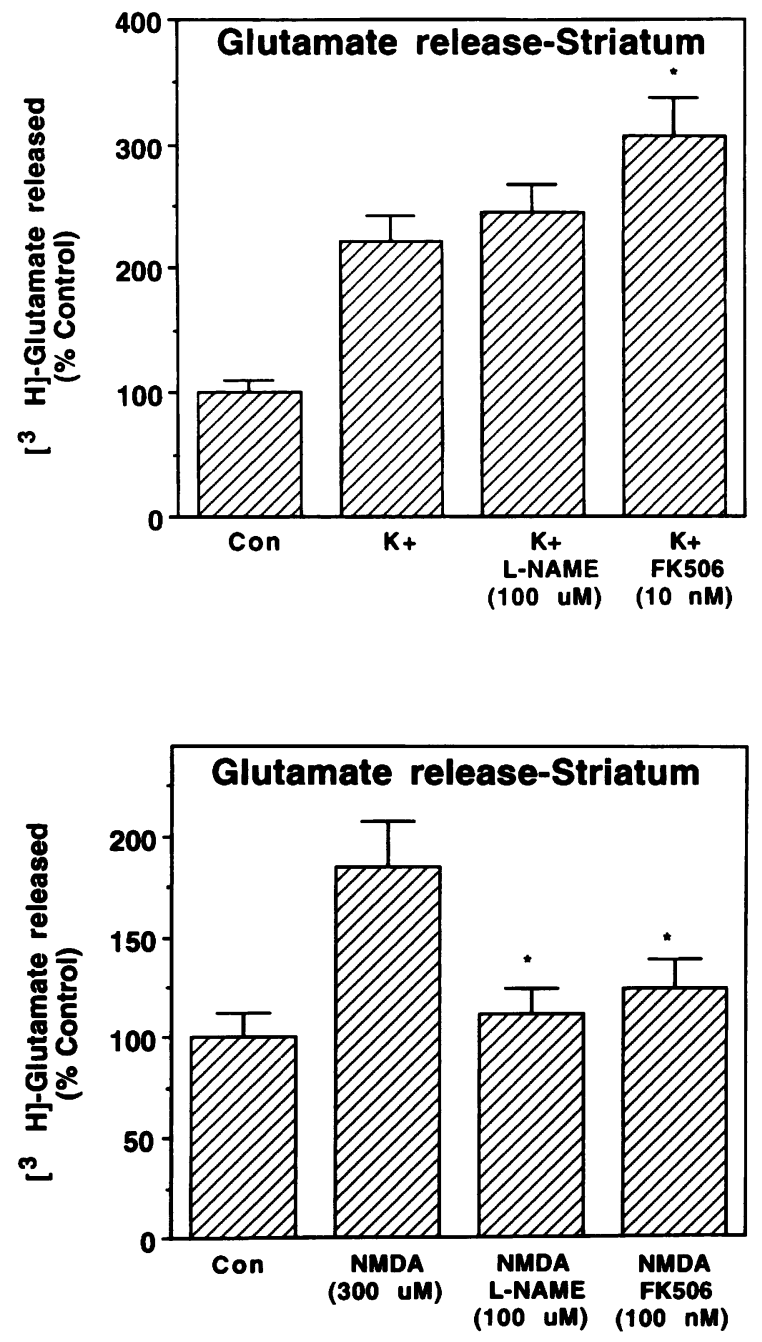

FIG. 2. Glutamate release from striatal synaptosomes

Synaptosomes were labeled with $\left[{ }^{3} \mathrm{H}\right]$-glutamate as described in Materials and Methods. Synaptosomes were preincubated with $100 \mathrm{mM}$ L-nitroarginine methyl ester (L-NAME) or $10 \mathrm{nM}$ FK506 for $5 \mathrm{~min}$ prior to release of $\left[{ }^{3} \mathrm{H}\right]$-glutamate elicited by addition of $40 \mathrm{mM} \mathrm{KCl}$. $\mathrm{KCl}$ depolarization release of glutamate is indicated by $\mathrm{K}^{+}$. Glutamate release was quantified as described in Materials and Methods. For NMDA-dependent release of glutamate, synaptosomes were washed in Mg-free NTR buffer and preincubated with L-NAME or FK506 for 5 min prior to addition of $300 \mathrm{mM}$ NMDA and $100 \mathrm{mM}$ glycine. After $2 \mathrm{~min}$, release of glutamate was quantified as described in Materials and Methods. *Statistically significant differences between drug treatment and either $\mathrm{KCl}$ or NMDA treated samples $(p<0.05$ using paired and unpaired Student's $t$ tests).

synaptosomes, since removal of extracellular calcium abolishes both depolarization dependent transmitter release and the effects of FK506 (data 

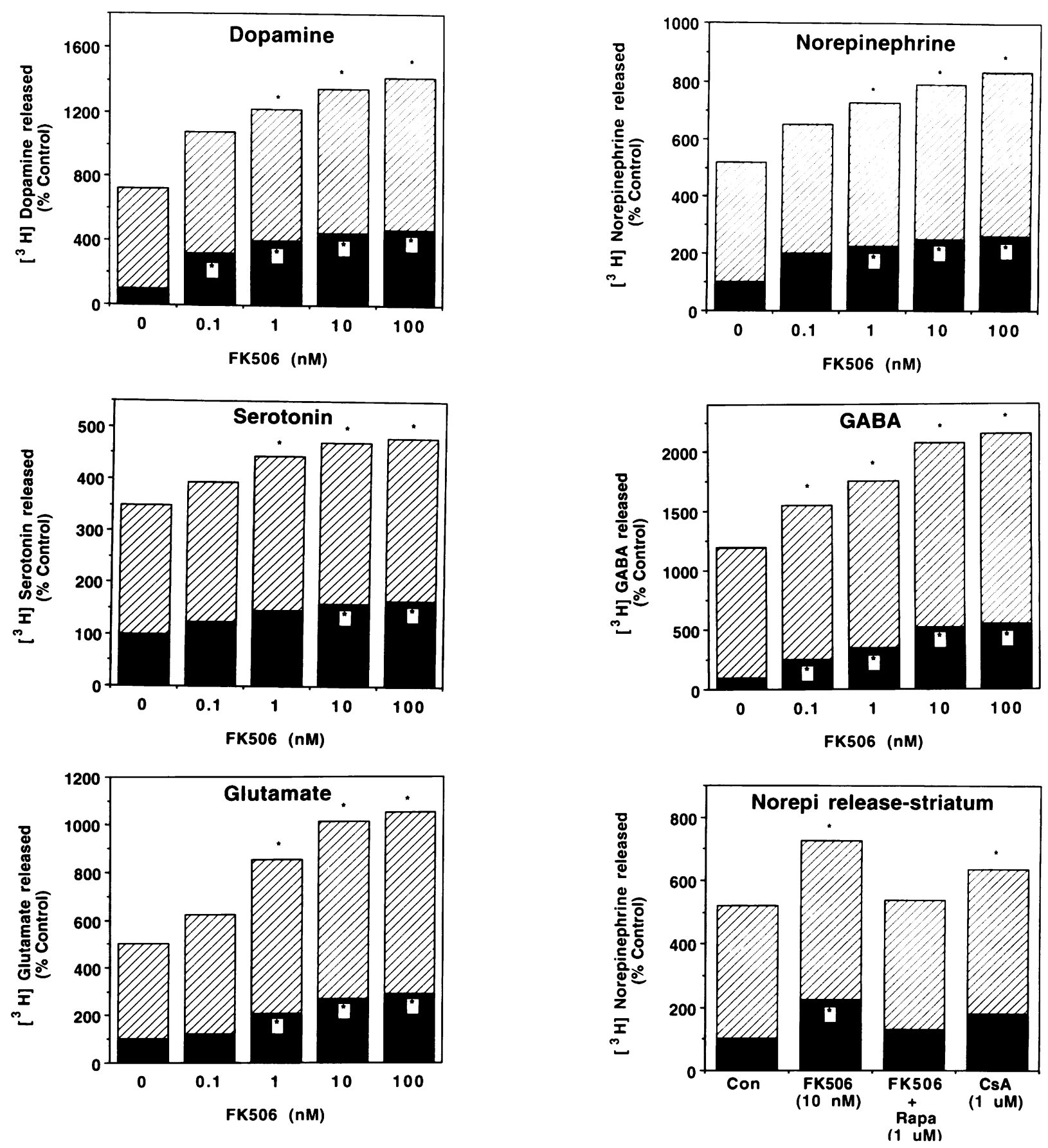

FIG. 3. FK506 enhances the basal and depolarization-dependent release of neurotransmitters from striatal synaptosomes

Striatal synaptosomes were labeled with $\left[{ }^{3} \mathrm{H}\right]$-dopamine, $\left[{ }^{3} \mathrm{H}\right]$-norepinephrine, $\left[{ }^{3} \mathrm{H}\right]$-serotonin, $\left[{ }^{3} \mathrm{H}\right]-\mathrm{GABA}$, or $\left[{ }^{3} \mathrm{H}\right]$-glutamate all from Dupont-NEN (Boston, MA) at $1 \mathrm{mCi} / \mathrm{ml}$ for $30 \mathrm{~min}$ at $37^{\circ} \mathrm{C}$, washed with NTR buffer and centifuged at $1,200 \times g$ for $15 \mathrm{~min}$. Synaptosomes were preincubated with the indicated concentrations of FK506 or FK506 + $1 \mathrm{mM}$ rapamycin for $5 \mathrm{~min}$ at $37^{\circ} \mathrm{C}$. After pretreatment, $\mathrm{KCl}$ or $\mathrm{NaCl}$ was added to $40 \mathrm{mM}$ final concentration to evoke neurotransmitter release. After 2 min release at $37^{\circ} \mathrm{C}$, synaptosomes were centrifuged at $10,000 \times g$ for $5 \mathrm{~min}$ and released $\left[{ }^{3} \mathrm{H}\right]$-neurotransmitter was recovered in the supernatant. The amount of transmitter released by addition of $\mathrm{NaCl}$ (basal release, black bars) in absence of drug treatment was designated $100 \%$ of control. Neurotransmitter released by addition of $\mathrm{KCl}$ is indicated by diagonal lined bars. *Statistically significant differences between drug treatment and basal and $\mathrm{K}^{+}$controls as indicated $(p<0.05$ using paired and unpaired Student's $t$ tests). 
not shown). The enhancement of norepinephrine release by FK506 is reversed by $100 \mathrm{nM}$ rapamycin, demonstrating the specificity of the FK506FKBP interaction and implicating the immunophilin FKBP as a mediator of the effects of FK506. $\left[{ }^{3} \mathrm{H}\right]$-norepinephrine release from hippocampal and cortical synaptosomes is also enhanced by FK506 (data not shown).

How might one account for the finding that FK506 fails to inhibit potassium depolarizationevoked release of neurotransmitter from synaptosomes whereas it blocks NMDA-induced release? NOS neurons possess NMDA receptors (17) and normally respond to NMDA with enhanced formation of NO, which would diffuse to adjacent nerve terminals to elicit transmitter release. While NMDA acts only on a subset of the synaptosomal population, potassium depolarization would influence all synaptosomes including those that lack NMDA receptors and NOS, so that any influence of FK506 on NO-regulated neurotransmission would be obscured.

In our experiments, FK506 stimulates both spontaneous and potassium depolarization-induced transmitter release in synaptosomes. This effect might involve synaptic vesicle proteins such as synapsin I, synaptobrevin, and synaptotagmin. Phosphorylation of synapsin I correlates with enhanced neurotransmitter release $(8,9)$. If phosphorylated proteins such as these are calcineurin substrates, then FK506 might enhance their phosphorylation, thereby facilitating transmitter release. In the crude synaptic vesicle fraction isolated from striatal synaptosomes, FK506 augments the phosphorylation state of several proteins including those with apparent SDSpolyacrylamide gel molecular weights of $50 \mathrm{kD}$, $58-60 \mathrm{kD}$, a doublet of about $70-75 \mathrm{kD}, 120 \mathrm{kD}$, and $350 \mathrm{kD}$ (Fig. 4). Immunoblot analysis indicates that the 70 - to $75-\mathrm{kD}$ doublet in synaptic vesicles is synapsin $\mathrm{I}$, whose increased phosphorylation state correlates well with increased glutamate release. FK506 treatment of synaptosomes leads to a $30-40 \%$ increase in ${ }^{32} \mathrm{P}$-phosphate incorporation into vesicle-bound synapsin I. Immunoprecipatation of ${ }^{32} \mathrm{P}$-phosphorylated synapsin I from striatal synaptosomes demonstrates that synapsin I contains $40-50 \%$ more phosphate following FK506 treatment (Fig. 4). Increased phosphorylation of synapsin I and these other synaptic vesicle proteins in the presence of FK506 indicates that they are calcineurin substrates.

\section{DISCUSSION}

The immunosuppressant drugs FK506 and cyclosporin A potently inhibit the release of neurotransmitters from PC 12 cells and NMDA-evoked release from rat brain synaptosomes. In the case of NGF-treated PC12 cells, where release of transmitter is dependent upon NO production, FK506 would inhibit NO production by inactivating NOS and reduce release of $\mathrm{ACh}$ and dopamine. The NO-dependent NMDA-stimulated release of glutamate from striatal synaptosomes is likewise blocked by FK506, presumably due to inhibition of NOS catalytic activity. Although the mechanism of the effects of FK506 on the release process in these cells is unknown, our data are consistent with the notion that the targets of FK506 and CsA are drug-immunophilin complexes binding to and inhibiting the protein phosphatase calcineurin.

NO apparently plays an inconsequential role in potassium depolarization-evoked release of neurotransmitters from rat brain synaptosomes. FK506 and CsA potentiate the release of the biogenic amines and amino acid neurotransmitters from rat brain synaptosomes. The FK506elicited transmitter release is blocked by rapamycin, indicating that FKBP participates in the release process. The calcineurin substrate synapsin I (18), whose phosphorylation is associated with transmitter release, is more highly phosphorylated in response to FK506 treatment, suggesting that phospho-synapsin I mediates FK506 enhancement of synaptosomal transmitter release. Several other unidentified phosphoproteins display elevated ${ }^{32} \mathrm{P}$ incorporation in response to FK506 and may also participate in the FK506 effects.

Blockade of calcineurin may also interfere with vesicle recycling. In response to $\mathrm{Ca}^{2+}$ entry calcineurin dephosphorylates several prominent nerve terminal proteins. Dynamin I, a phosphoprotein with intrinsic guanosine triphosphatase (GTPase activity), is required for endocytosis and is a substrate for calcineurin $(19,20)$. In nerve terminals, calcineurin may serve as a $\mathrm{Ca}^{2+}$-sensitive switch for depolarization-evoked synaptic vesicle recycling $(19,20)$. In this way, calcineurin could reset the nerve terminal for the next round of depolarization-induced neurotransmitter release.

FK506 and CsA enhancement of neurotransmitter may have diverse physiologic consequences. Long-term potentiation (LTP) and longterm depression (LTD), which participate in 

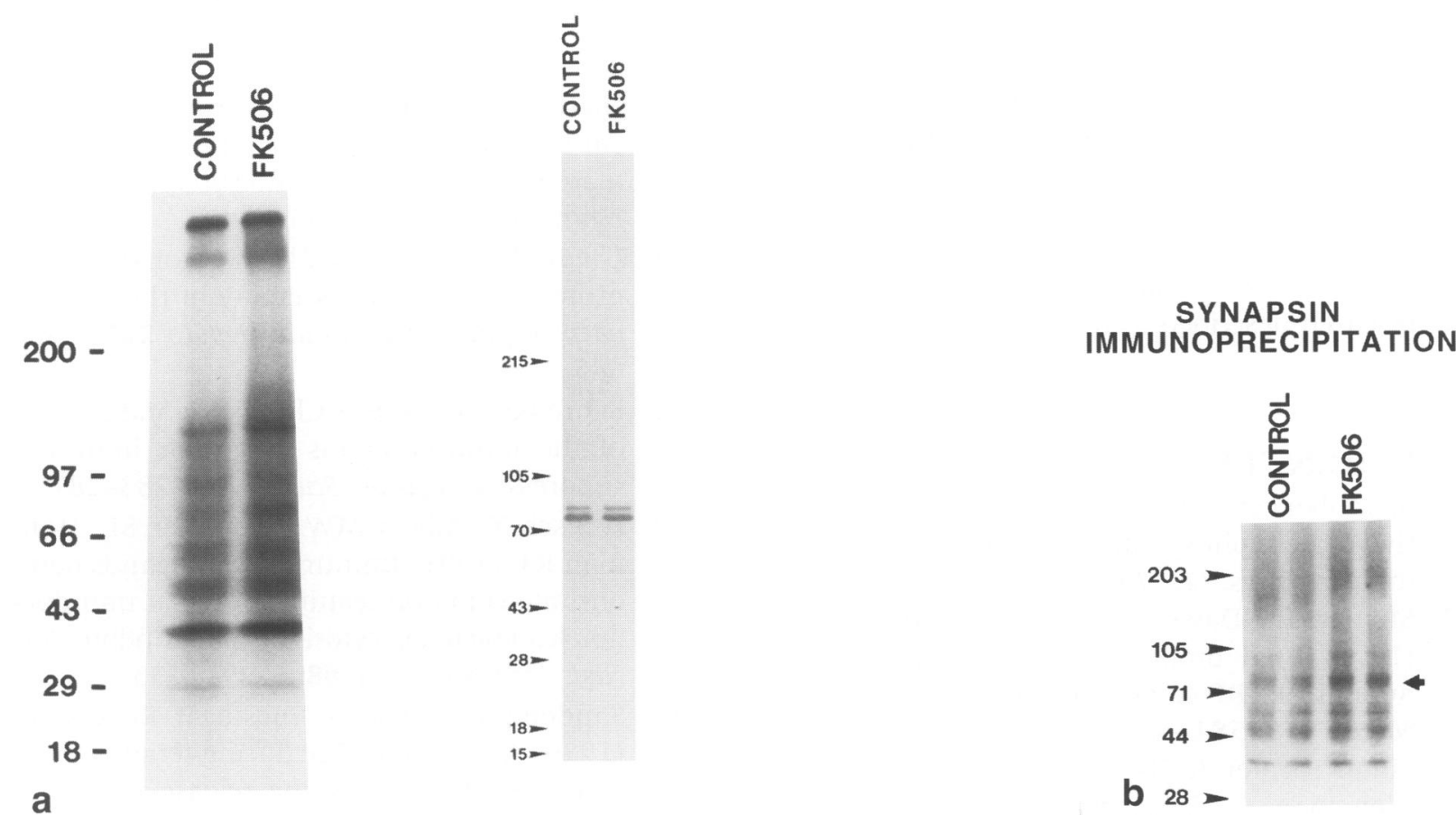

FIG. 4. Phosphorylation of synaptosomal proteins

(a) Striatal synaptosomal proteins were preincubated with ${ }^{32} \mathrm{P}$-orthophosphate and phosphorylation monitored in the presence of $100 \mathrm{nM}$ FK506. Synaptosomes were lysed, and the crude synaptic vesicle fraction was recovered following centrifugation as described in Materials and Methods. The ${ }^{32} \mathrm{P}$-labelled synaptic vesicle proteins from untreated and 100 nM FK506-treated synaptosomes were resolved by gel electrophoresis, the gels were dried, and an autoradiogram was prepared. Immunoblot analysis of these samples probed with anti-synapsin I Ig demonstrated equivalent amounts of synapsin in each fraction. Molecular weight markers in kilodaltons are indicated. (b) ${ }^{32} \mathrm{P}$ labelled synapsin I was immunoprecipitated from phosphorylated striatal synaptosomes treated with FK506 or buffer containing $0.01 \%$ ethanol (the vehicle for FK506) as described in Materials and Methods. Duplicate samples of anti-synapsin I immunoprecipitates from control and FK506-treated synaptosomes were resolved by gel electrophoresis, gels dried down, and an autoradiogram was prepared. Synapsin I is indicated by the arrow at 73-75 kDa. Molecular weight markers are indicated in kilodaltons.

learning and information storage, are regulated by calcium-dependent phosphorylation/dephosphorylation (21). Calcineurin has been implicated in the generation of LTD in hippocampal slices, as FK506 inhibits this process (22). Generation of LTD requires activation of postsynaptic NMDA receptors (23), which also increases glutamate release. Thus, inhibition of LTD by FK506 may reflect altered release of neurotransmitters associated with increased phosphorylation of calcineurin substrate phosphoproteins, including NOS.

Transplant patients receiving FK506 or CsA develop a variety of side effects, such as hyper- tension, which is thought to be due to increased sympathetic tone (24). Enhancement of norepinephrine release by FK506 and CsA could account for increased sympathetic tone and hypertension.

\section{ACKNOWLEDGMENTS}

This work was supported by USPHS Grant DA00266, Research Scientist Award DA-00074 (SHS), and postdoctoral fellowship MH10101 (JPS). TMD was supported by USPHS CIDA NS 04578 and the Beeson Scholar Program in Aging 
Research. We gratefully acknowledge Dr. Samuel Danishefsky for the gift of FK506, WyethAyerst for the gift of rapamycin, and Sandoz for cyclosporin A used in these studies. The expert technical assistance of Roxanne Barrow is gratefully acknowledged. We also thank Nancy Bruce for preparing the manuscript. Some of the authors own stock in and are entitled to royalties (JPS, TMD, SHS) from Guilford Pharmaceuticals, Inc., which is developing technology related to the research described in this paper.

\section{REFERENCES}

1. Schreiber SL. (1992) Immunophilin-sensitive protein phosphatase action in cell signaling pathways. Cell 70: 365-368.

2. Steiner JP, Dawson TM, Fotuhi M, et al. (1992) High brain densities of the immunophilin FKBP colocalized with calcineurin. Nature 358: 584-587.

3. Liu J, Farmer Jr JD, Lane WS, Friedman J, Weissman I, Schreiber SL. (1991) Calcineurin is a common target of cyclophilincyclosporin A and FKBP-FK506 complexes. Cell 66: 807-815.

4. Dawson TM, Steiner JP, Dawson VL, Dinerman JL, Uhl GR, Snyder SH. (1993) Immunosuppressant, FK506, enhances phosphorylation of nitric oxide synthase and protects against glutamate neurotoxicity. Proc. Natl. Acad. Sci. U.S.A. 90: 9808-9812.

5. Dawson VL, Dawson TM, London ED, Bredt DS, Snyder SH. (1991) Nitric oxide mediates glutamate neurotoxicity in primary cortical culture. Proc. Natl. Acad. Sci. U.S.A. 88: 63686371.

6. Hanbauer I, Wink D, Osawa Y, Edelman GM, Gally J. (1992) Role of nitric oxide in NMDA-evoked release of $\left[{ }^{3} \mathrm{H}\right]$-dopamine from striatal slices. NeuroReport 3: 409-412.

7. Hirsch DB, Steiner JP, Dawson TM, Mammen A, Hayek E, Snyder SH. (1993) Neurotransmitter release regulated by nitric oxide in PC-12 cells and brain synaptosomes. Curr. Biol. 3: 749-754.

8. Llinas R, McGuinness TL, Leonard CS, Sugimori M, Greengard P. (1985) Intraterminal injection of synapsin I or calcium/calmodulindependent protein kinase II alters neurotransmitter release at the squid giant synapse. Proc. Natl. Acad. Sci. U.S.A. 82: 3035-3039.

9. Llinas R, Gruner JA, Sugimori M, McGuinness TL, Greengard P. (1991) Regulation by synapsin $\mathrm{I}$ and $\mathrm{Ca}^{2+} /$ calmodulin-dependent protein kinase II of transmitter release in squid giant synapse. J. Physiol. (Lond.) 436: 257-282.

10. Nichols RA, Chilcote TJ, Czernik AJ, Greengard P. (1992) Synapsin I regulates glutamate release from rat brain synaptosomes. $J$. Neurochem. 58: 783-785.

11. Laemmli UK. (1970) Cleavage of structural proteins during the assembly of the head of bacteriophage T4. Nature (Lond.) 227: 680685.

12. Schreiber SL. (1991) Chemistry and biology of the immunophilins and their immunosuppressive ligands. Science 253: 283-287.

13. Hultsch T, Albers MW, Schreiber SL, Hohman RJ. (1991) Immunophilin ligands demonstrate common features of signal transduction leading to exocytosis or transcription. Proc. Natl. Acad. Sci. U.S.A. 88: 6229-6233.

14. Sandberg K, Berry CJ, Eugster E, Rogers TB. (1989) A role for cGMP during tetanus toxin blockade of acetylcholine release in the rat pheochromocytoma (PC12) cell lines. J. Neurosci. 9: 3946-3954.

15. Sandberg K, Berry CJ, Rogers TB. (1989) Studies on the intoxication pathway of tetanus toxin in the rat pheochromocytoma (PC12) cell line. J. Biol. Chem. 264: 56795686.

16. Dinerman J, Steiner JP, Dawson TM, Dawson V, Snyder SH. (1994) Cyclic nucleotide dependent phosphorylation of neuronal nitric oxide synthase inhibits catalytic activity. Neuropharmacology 33: 1245-1251.

17. Marin P, Lafon-Cazal M, Bockaert J. (1992) A nitric oxide synthase activity selectively stimulated by NMDA receptors depends on protein kinase $C$ activation in mouse striatal neurons. Eur. J. Neurosci. 4: 425-432.

18. King MM, Huang CY, Chock BP, et al. (1984) Mammalian brain phosphoproteins as substrates for calcineurin. J. Biol. Chem. 259: $8080-8083$.

19. Nichols RA, Suplick GR, Brown JM. (1994) Calcineurin-mediated protein dephosphorylation in brain nerve terminals regulates the release of glutamate. J. Biol. Chem. 269: 23817-23823.

20. Liu JP, Sim AT, Robinson PJ. (1994) Calcineurin inhibition of dynamin I GTPase activity coupled to nerve terminal depolarization. Science 265: 970-973.

21. Bliss TVP, Collingridge GL. (1993) A synaptic 
model of memory: Long-term potentiation in the hippocampus. Nature 361: 31-39.

22. Mulkey RM, Endo S, Shenolikar S, Malenka RC. (1994) Involvement of a calcineurin/ inhibitor-1 phosphatase cascade in hippocampal long-term depression. Nature 369: $486-488$.

23. Dudek S, Bear MF. (1992) Homosynaptic long-term depression in area CA 1 of hip- pocampus and effects of $\mathrm{N}$-methyl-D-aspartate receptor blockade. Proc. Natl. Acad. Sci. U.S.A. 89: 4363-4367.

24. Lyson T, Ermel LD, Belshaw PJ, Alberg DG, Schreiber SL, Victor RG. (1993) Cyclosporine- and FK506-induced sympathetic activation correlates with calcineurin-mediated inhibition of T-cell signaling. Circ. Res. 73: 596-602.

Contributed by S. H. Snyder on January 29, 1996. 